\title{
Modeling of the Internal Temperature for an Energy Saving Chinese Solar Greenhouse
}

\author{
Jamilu Yau \\ College of Information and \\ Electrical Engineering, Shenyang \\ Agricultural University, Shenyang, \\ China and Dpt. of Electrical \\ Engineering, Bayero University \\ Kano, Kano State, Nigeria \\ Olubakinde Eniola \\ Department of Electrical and Electronic Engineering \\ Federal Polytechnic Ile-Oluji \\ Ondo State, Nigeria

\begin{abstract}
The global rise in food demand requires urgent attention in the aspect of crop production. The microclimate of a greenhouse is a critical issue in agricultural practice, due to the variations of the external climatic conditions and their negative effect on crop production. In this work, a dynamic model of the internal air temperature of a Chinese solar greenhouse was designed in Matlab/Simulink environment. The dynamic model was designed with the use of energy balance equations. The weather data consisting of solar radiation, relative humidity, ambient temperature, and Photosynthetically Active Radiation (PAR) were acquired from meteorological stations. The results of the simulations show that the temperature of the internal air varies with weather conditions, location, number of covers, and the structure of the solar greenhouse.
\end{abstract}

\author{
Ji JianWei \\ College of Information and \\ Electrical Engineering \\ Shenyang Agricultural University \\ Shenyang, China
}

\author{
Hui Wang \\ College of Information and \\ Electrical Engineering \\ Shenyang Agricultural University \\ Shenyang, China
}

Keywords-Chinese solar greenhouse; dynamic model; relative humidity; temperature; agricultural practices; external climatic conditions

\section{INTRODUCTION}

A greenhouse is defined as a covered structure that provides plants with an optimally controlled environment for adjustment of climate growth conditions, in order toreduce production cost and increase crop yield. Global food production systems depend on the proper utilization of greenhouses. Many greenhouse types are successfully used for plant protection worldwide. Some may be better than others for particular applications, but no greenhouse type is considered the best [1] Control of the micro-climate of the greenhouse is essential in order to encourage crop production considering the unstable nature of temperature, relative humidity, $\mathrm{CO}_{2}$ concentration, and solar radiation [2-8]. The possibilities offered by greenhouse climate computers have solved the problems relating to the regulation and respect of climate instructions required by protected cultivation. The greenhouse climate computer will have to be integrated as a tool for the dynamic management of production, able to choose the most appropriate climate route, meet objectives and production orders while minimizing inputs. Computers have become quite popular in greenhouse management, even in countries where environmental conditions do not inhibit the development of plants. In developed countries, computers find a lot of application in irrigation, boilers and climate control, where they are used to regulate humidity, $\mathrm{CO}_{2}$, and artificial lighting. The computers are used to determine climate set points and to monitor alarm functions. The literature on control theory and application of classical dynamic systems in the entire field of greenhouse control and modeling is sufficient [9].

The microclimate parameters inside a greenhouse are air temperature, soil temperature in addition to the soil sub-layer, relative humidity, and $\mathrm{CO}_{2}$ concentration. They can be predicted experimentally or by simulation [10]. The evolution of the greenhouse model is fast and conducted by the control of the energy phenomena involved inside. In the literature, the modeling of the thermal energy balance can be static [11] or dynamic. Various dynamic models of greenhouses have been developed [12, 13]. To overcome the less optimal climate conditions and to fulfil the specific environmental needs of various crops, energy saving greenhouse designs vary in structural shape, size, glazing materials, and in the type of equipment required to achieve the desired environmental conditions.

In the current research, the simplified dynamic model of the energy balance for a Chinese solar greenhouse is developed under the Matlab-Simulink environment.

\section{MATERIALS AND METHODS}

\section{A. Description}

Since the focus of the design method is to model the internal temperature of the greenhouse, the set of design 
elements and the selected functions and techniques are incorporated in the greenhouse climate model. In this model, heating is provided by the solar radiation and the heat storage system which influence the internal temperature and the temperature of the heating pipes. Cooling and $\mathrm{CO}_{2}$ are provided by natural ventilation. A typical greenhouse consists of soil, cover, crop, and internal air. In this research, the crop is neglected. The actual experimental greenhouse is located in Shenyang, Liaoning, China. The new energy saving solar greenhouse assembled with rock wool color plate uses a double-layer semi-circular arc steel structure. The inner layer is covered with a transparent material of $0.1 \mathrm{~mm}$ thick polyolefin (PO) film and the insulation cover on the outer layer is made up of rock wool color plate. In the low temperature season, the insulation covers on the outer layer are slid down, thus retaining heat and reducing heat loss effectively [14].

\section{B. The Dynamic Model of the Chinese Solar Greenhouse}

Simplified models of the Chinese greenhouse have been developed in [15-17]. The main objective of a climate control system is to maintain the temperature inside the greenhouse within a suitable range [18]. The layout for the Chinese greenhouse in Figure 1 shows the external and the internal parameters, where all the modelled elements have been schematized. The grey boxes indicate the calculated temperatures (state variables) while the white boxes represent the independent variables linked to the model with an external file (csv format) or are directly calculated.

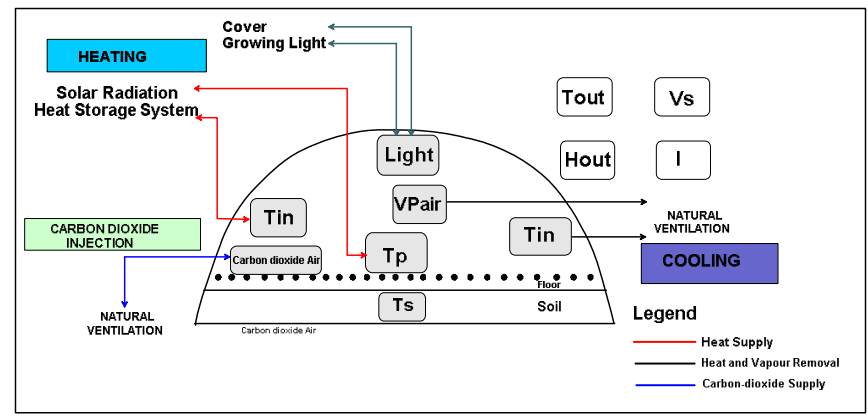

Fig. 1. Layout of a typical Chinese solar greenhouse.

The model is based on the following assumptions:

- The outdoor weather conditions (white boxes in Figure 1) are not influenced by the greenhouse indoor climate.

- Each span in the multi span glasshouse has the same layout with respect to the configuration of the heating pipes, the artificial lighting system, and its size.

- The greenhouse air is considered as a "perfectly stirred tank", which means that there are no temperature gradients or water vapour concentration differences, therefore all the model fluxes can be described per square meter.

- All modelled elements (state variables) are homogeneous: they have a uniform temperature and an average thermal capacity can be used.

When the transport of physical quantities like energy and mass is considered, for these quantities the law of conservation is valid for any volume. To establish a general rule, energy is considered first [18]. If an amount of energy per unit of time $\left(q_{\mathrm{h}}\right.$, energy flux, $\left.\mathrm{Js}^{-1}\right)$ enters a volume, then the amount of energy in the volume $Q_{\mathrm{h}}(\mathrm{J})$ will increase. Of course if an energy flux leaves a volume, $Q_{\mathrm{h}}$ will decrease. The relation in which we compare the entering and leaving fluxes is called balance. We can set up an energy balance or a mass balance and for any volume. Not only the inflows and outflows of energy contribute to the increase or decrease of the energy in the volume, but also the energy production in the volume $p_{\mathrm{h}}$ $\left(\mathrm{Js}^{-1}\right)$, if any. From these considerations the energy balance over any volume can be set up in general terms as:

$$
\frac{d Q_{h}}{d t}=q_{\text {in }, h}-q_{\text {out }, h}+p_{h}
$$

The term on the left is the change of energy per unit of time in the considered volume. It is determined by the terms on the right hand side, which are respectively the influx, the outflows and the production of energy per unit of time in the considered volume. It is assumed that no work is done by or on the medium in the volume, which in general is true for the greenhouse situation [18]. The amount of energy in the volume $Q_{\mathrm{h}}$ (internal energy) is directly related to the temperature $T(\mathrm{~K})$ of the volume through its thermal capacity $\operatorname{Cap}_{\mathrm{h}}\left(\mathrm{JK}^{-1}\right)$ :

$$
Q_{h}=\operatorname{Cap}_{h} T
$$

In this way the time rate of change of the internal energy is translated to a time rate of change of temperature that can be implemented in the balance:

$$
\begin{gathered}
\operatorname{Cap}_{h} d T / d t=q_{\text {in }, h}-q_{\text {out }, h}+p_{h} \\
\operatorname{Cap}_{h}=\rho V C_{p} \\
p_{h}=0 \\
q_{\text {in }, h}=Q_{\text {short }} \quad(5) \\
q_{\text {out }, h}=Q_{\text {infilt }}+Q_{\text {cond }, \text { conv }}+Q_{\text {long }}
\end{gathered}
$$

where $Q_{\text {short }}$ is the heat gained by solar radiation, $Q_{\text {heater }}$ is the heat gained by the heater, $Q_{\text {vent }}$ is the heat loss through ventilation, $Q_{\text {cond,conv }}$ is the heat loss through conduction and convection, and $Q_{\text {long }}$ is the heat loss due to the longwave radiation. Solar radiation is the main heat source for a greenhouse and can be calculated as:

$$
Q_{\text {short }}=\alpha_{c} \tau_{c} S I
$$

where $\alpha_{c}$ is the cover's absorptivity, $\tau_{c}$ is the cover's transmittance, $S$ is the cover's surface area, and $I$ is the total solar radiation. $Q_{\text {inflit }}$ is the heat loss by infiltration:

$$
Q_{\text {infilt }}=\rho_{a} C_{a} R \frac{\left(T_{\text {in }}-T_{\text {out }}\right)}{3600}
$$

where $\rho_{a}$ is the density of the air, $C_{a}$ is the specific heat of the air, $R$ is the number of air changes per hour, $T_{i n}$ is the indoor air temperature $\left({ }^{\circ} \mathrm{C}\right)$ and $T_{\text {out }}$ is the external temperature. The heating pipe energy exchange belongs to the convective heat transfer which follows the Newton's law of cooling [19]:

$$
Q_{\text {heater }}=1.95 A_{p}\left(T_{p}-T_{\text {in }}\right)^{4 / 3}
$$


where $\rho_{a}$ is the density of the air, $C_{a}$ is the specific heat of the air, $R$ is the number of air changes per hour, $T_{i n}$ is the indoor air temperature $\left({ }^{\circ} \mathrm{C}\right)$, and $T_{\text {out }}$ is the external temperature $\left({ }^{\circ} \mathrm{C}\right)$.

$$
\begin{gathered}
Q_{\text {vent }}=\rho C_{a} Q\left(T_{\text {in }}-T_{\text {out }}\right) \\
Q=\frac{(1-\delta) \tau_{c} S_{o} A_{f}-U S\left(T_{\text {in }}-T_{\text {out }}\right)}{C_{a}\left(T_{\text {in }}-T_{\text {out }}\right)}
\end{gathered}
$$

where $\delta$ is the evaporation coefficient $(-), \tau_{c}$ is the average transmittance of the greenhouse cover of solar radiation (-), $S_{o}$ is the solar radiation flux outside the greenhouse $\left(\mathrm{Wm}^{-2}\right), A_{f}$ is the surface area of the greenhouse floor $\left(\mathrm{m}^{2}\right), U$ is the overall heat loss coefficient of the cover $\left(\mathrm{Wm}^{-2 \circ} \mathrm{C}^{-1}\right), S$ is the surface area of the greenhouse cover $\left(\mathrm{m}^{2}\right), T_{\text {in }}$ is the internal temperature, $T_{\text {out }}$ is the external temperature, and $C_{a}$ is the specific heat of the air at constant pressure $\left(\mathrm{J}^{\mathrm{kg}}{ }^{-1}{ }^{\circ} \mathrm{C}\right)$.

$$
Q_{\text {cond,conv }}=U S\left(T_{\text {in }}-T_{\text {out }}\right)
$$

where $U$ is the overall heat transfer coefficient through the greenhouse walls and computed by:

$$
U=\left[\frac{1}{h_{0}}+\frac{L_{C}}{K_{c}}+\frac{1}{h_{i}}\right]^{-1}
$$

where $h_{0}$ is the convective heat transfer coefficient of the outside greenhouse cover, $h_{i}$ is the convective heat transfer of the inside greenhouse cover, $L_{c}$ is the cover thickness, and $K_{c}$ is the heat transfer coefficient of polyolefin cover. For $h_{0}$ and $h_{i}$, (15) and (16) apply:

$$
\begin{gathered}
h_{0}=2.8+1.2 V_{w} \\
h_{i}=1.52\left|T_{\text {in }}-T_{\text {out }}\right|^{1 / 3}+5.2\left(\frac{R}{S_{c} L}\right)^{1 / 2}
\end{gathered}
$$

where $V_{w}$ is the wind velocity, $L$ is the length of the greenhouse, and $S_{c}$ is the vertical section of the greenhouse. The long-wave thermal radiation from the greenhouse covering to the sky follows the Stefan - Boltzman's law:

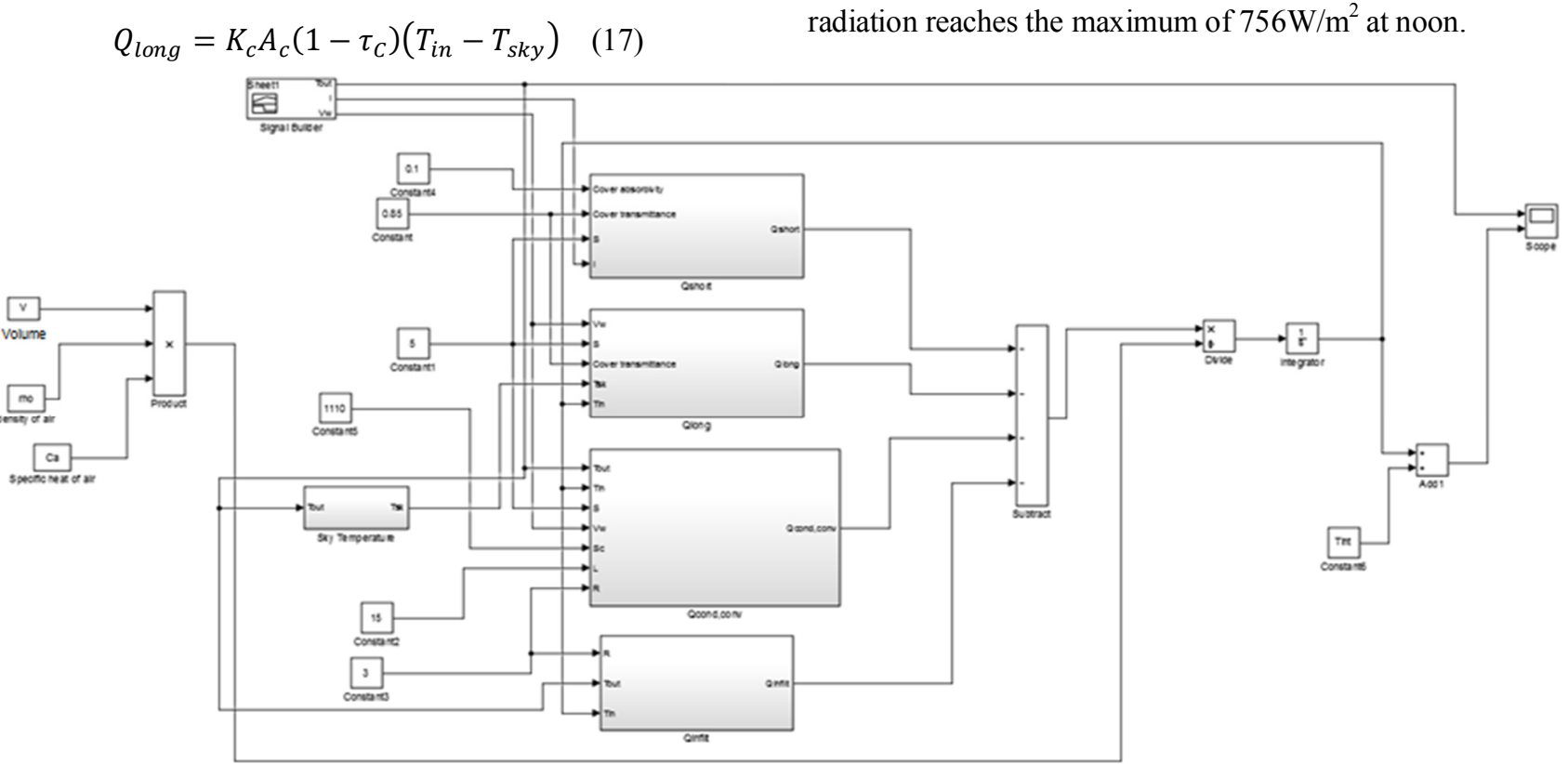

Fig. 2. Dynamic model of the Chinese greenhouse in Simulink. where $K_{c}$ is the heat transfer coefficient of the cover, $A_{c}$ is the area of the cover, $\tau_{c}$ is the transmittance of the cover, $T_{i n}$ is the internal temperature, and $T_{s k y}$ is the sky temperature.

$$
\begin{gathered}
T_{\text {sky }}=0.0552\left(T_{\text {out }}\right)^{1.5} \\
\rho V C_{p} d T_{\text {in }} / d t=Q_{\text {short }}+Q_{\text {heater }}-Q_{\text {vent }} \\
-Q_{\text {cond }, \text { conv }}-Q_{\text {long }} \text { (19) } \\
d T_{\text {in } / d t}=\frac{Q_{\text {short }}+Q_{\text {heater }}-Q_{\text {vent }}-Q_{\text {cond }, \text { conv }}-Q_{\text {long }}}{\rho V C_{p}} \\
T_{\text {in }}=\int \frac{Q_{\text {short }}+Q_{\text {heater }}-Q_{\text {vent }}-Q_{\text {cond,conv }}-Q_{\text {long }}}{\rho V C_{p}}+T_{i, 0}
\end{gathered}
$$

where $V$ is the volume of the greenhouse $\left(\mathrm{m}^{3}\right), \rho$ is the air density $\left(\mathrm{kg} / \mathrm{m}^{3}\right) C_{p}$ is the specific heat capacity of the air $\left(\mathrm{J} / \mathrm{Kg}^{\circ} \mathrm{C}\right)$ and $T_{i, 0}$ is the initial value of the greenhouse temperature $\left({ }^{\circ} \mathrm{C}\right)$.

\section{THE DEVELOPED MODEL}

The dynamic knowledge model of the energy balance of the new energy saving greenhouse described above is shown in Figure 2. The simulation was performed using a weather database that was acquired in the Shenyang Liaoning, China during the period from April, 2016 to April, 2017 with a sampling time equal to 10 minutes and was divided into 3-day and 5-day intervals to enable faster simulation. This database includes the measurements of solar radiation, outside temperature, relative humidity, vapor pressure deficit, wind velocity, dew point and Photo synthetically Active Radiation (PAR). The signal generator in the Simulink was used to import the external database into it, thus allowing the calculation of the air temperature inside the greenhouse model. The input parameters used are summarized in Table I. The subsystems generated in Simulink are shown in Figures 3-6. These subsystems depict how the different blocks in the Simulink environment were connected. The level of solar radiation reaches the maximum of $756 \mathrm{~W} / \mathrm{m}^{2}$ at noon. 
TABLE I. SIMULATION PARAMETERS

\begin{tabular}{|c|c|c|c|}
\hline Symbol & Numerical value & Units & Description \\
\hline$K_{C}$ & 0.028 & $\mathrm{Wm}^{-2} \mathrm{~K}^{-1}$ & Heat transfer coefficient of the cover \\
\hline$A_{C}$ & 1123.1 & $\mathrm{~m}^{2}$ & Area of the greenhouse cover \\
\hline$T$ & - & $\mathrm{K}$ or ${ }^{\circ} \mathrm{C}$ & Temperature \\
\hline$\varepsilon$ & 0.9 & 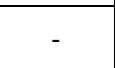 & $\begin{array}{l}\text { Emissivity between the cover and the } \\
\text { sky }\end{array}$ \\
\hline$\sigma$ & 0.0000000567 & - & Stefan-Boltzmann constant \\
\hline$\rho$ & 1.2 & $\mathrm{Kg} / \mathrm{m}^{3}$ & Air density \\
\hline$C p$ & 1006 & $\mathrm{JKg}^{-1} \mathrm{~K}^{-1}$ & Specific heat of the air \\
\hline$Q$ & - & $\mathrm{m}^{3} / \mathrm{s}$ & Air flow due to ventilation \\
\hline$V$ & 3088.6 & $\mathrm{~m}^{3}$ & Greenhouse volume \\
\hline$A_{f}$ & 715 & $\mathrm{~m}^{2}$ & Surface area of the greenhouse floor \\
\hline$\tau_{C}$ & 0.87 & - & Transmittance of the cover \\
\hline$I$ & - & $\mathrm{Wm}^{-2}$ & $\begin{array}{c}\text { Total solar energy falling on } \\
\text { horizontal surface }\end{array}$ \\
\hline$A_{P}$ & 73.9 & $\mathrm{~m}^{2}$ & Surface area of hot water pipes \\
\hline$A_{W}$ & 95.033 & $\mathrm{~m}^{2}$ & Surface area of back and front walls \\
\hline$U$ & - & $\mathrm{Wm}^{-2} \mathrm{~K}^{-1}$ & $\begin{array}{l}\text { Overall heat transfer coefficient } \\
\text { through the greenhouse walls }\end{array}$ \\
\hline$S$ & 5 & $\mathrm{~m}^{2}$ & Surface area of the greenhouse cover \\
\hline$h_{i}$ & & $\mathrm{Wm}^{-2} \mathrm{~K}^{-1}$ & $\begin{array}{l}\text { Convective heat transfer coefficient of } \\
\text { the inside greenhouse cover }\end{array}$ \\
\hline$h_{0}$ & & $\mathrm{Wm}^{-2} \mathrm{~K}^{-1}$ & $\begin{array}{l}\text { Convective heat transfer coefficient of } \\
\text { the inside greenhouse cover }\end{array}$ \\
\hline$L_{C}$ & & $\mathrm{~m}$ & Cover thickness \\
\hline$L$ & & $\mathrm{~m}$ & Greenhouse length \\
\hline$R$ & 3 & $\mathrm{~m}^{3} / \mathrm{s}$ & Number of air changes per hour \\
\hline$S_{C}$ & & $\mathrm{~m}^{2}$ & Vertical section of the greenhouse \\
\hline$\alpha_{c}$ & 0.1 & - & Cover absorptivity of solar radiation \\
\hline
\end{tabular}

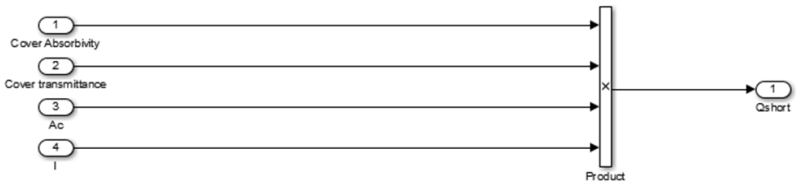

Fig. 3. Sub-system for the heat gained by solar radiation $\left(Q_{\text {short }}\right)$.

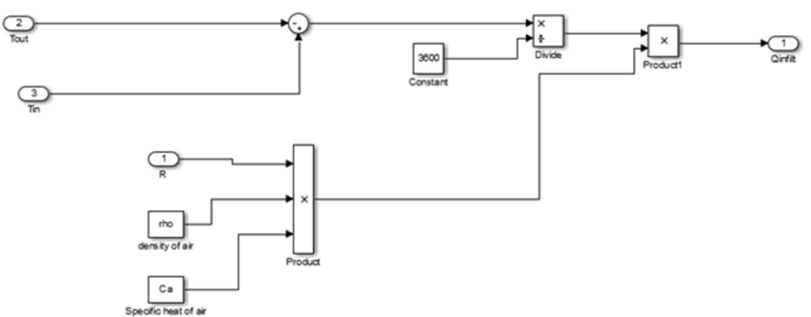

Fig. 4. Sub-system for $Q_{\text {infilt }}$.

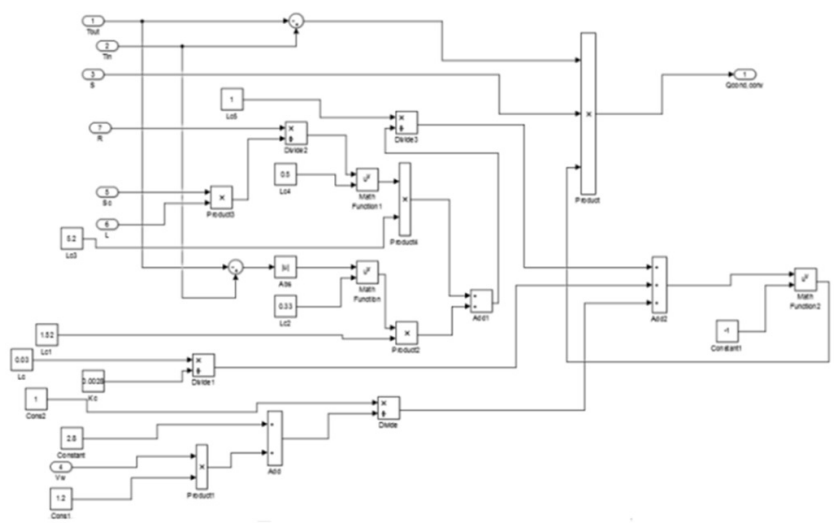

Fig. 5. Sub-system for $Q_{\text {cond,conv }}$.
Parts of the simulation results of internal and external temperature are shown in Figures 7-9. The points where a decrease in internal temperatures is noticed coincide with the regions of lower external temperatures, confirming the validity of the simulation results.

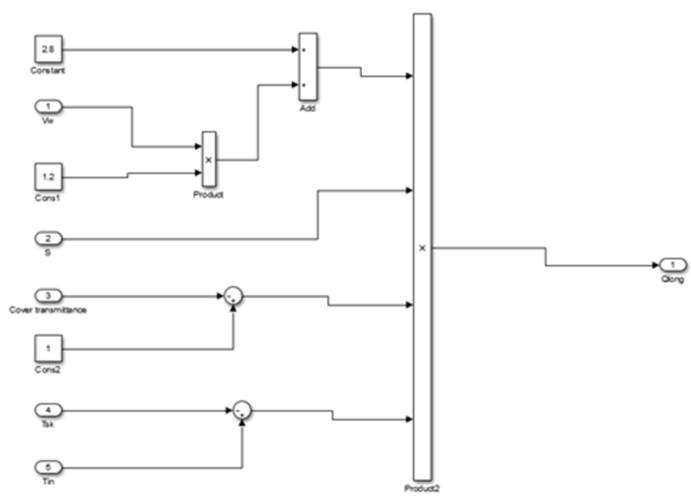

Fig. 6. Heat loss due to longwave radiation $\left(Q_{\text {long }}\right)$.

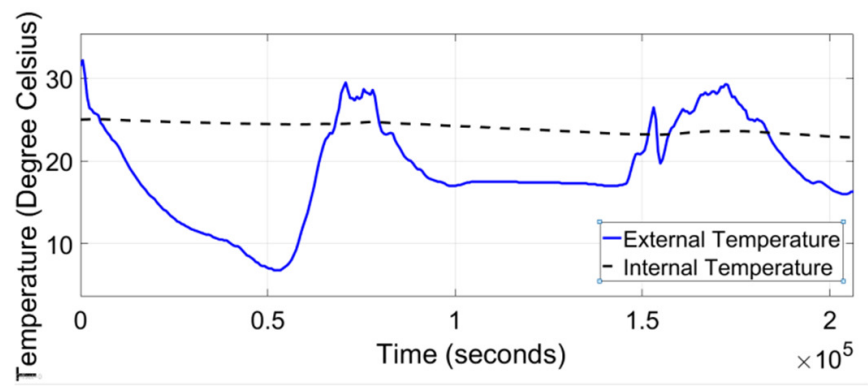

Fig. 7. Simulation results obtained during 28-30 April 2016. Temperatures were recorded every 10 minutes.

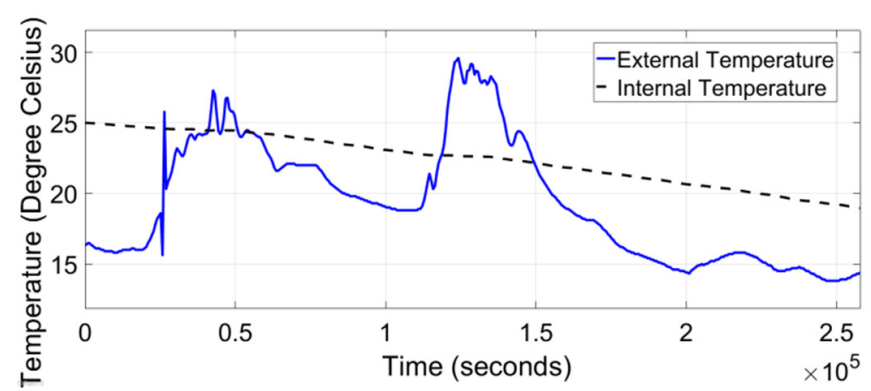

Fig. 8. Simulation results obtained during 1-3 May 2016. Temperatures were recorded every 10 minutes.

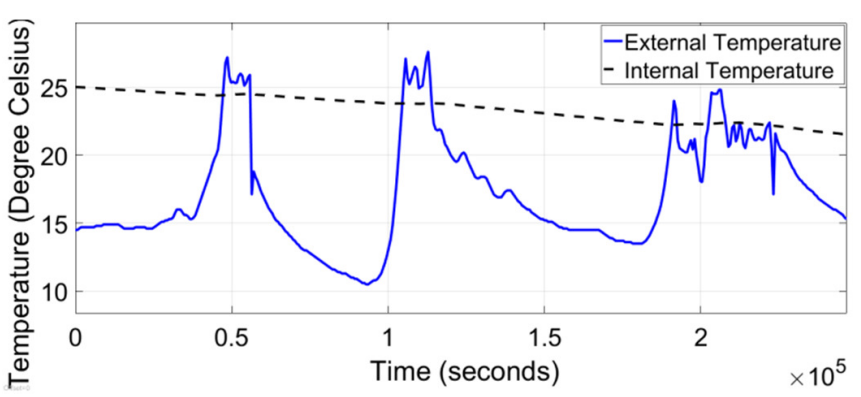

Fig. 9. Simulation results obtained during 4-6 May 2016. Temperatures were recorded every 10 minutes. 
The variation of the external solar radiation and the external temperature are displayed with the use of the signal generator block in the Simulink environment, as shown in Figures 10-12, which show the hourly variation of solar radiation in the greenhouse and the temperature profile of its different components. The greenhouse outside temperature varied from $6.8^{\circ} \mathrm{C}$ to $32.2^{\circ} \mathrm{C}$, Solar radiation contributed significantly to greenhouse outside temperature fluctuations.

External Temperature and Solar Radiation Profile for 28 - 30 April, 2016

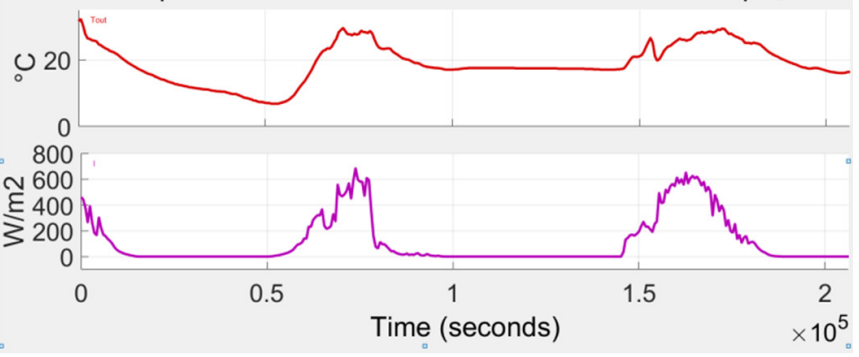

Fig. 10. (a) External temperature profile, (b) solar radiation profile for 28 30 April, 2016.

External Temperature and Solar Radiation Profile for 1 - 3 May, 2016

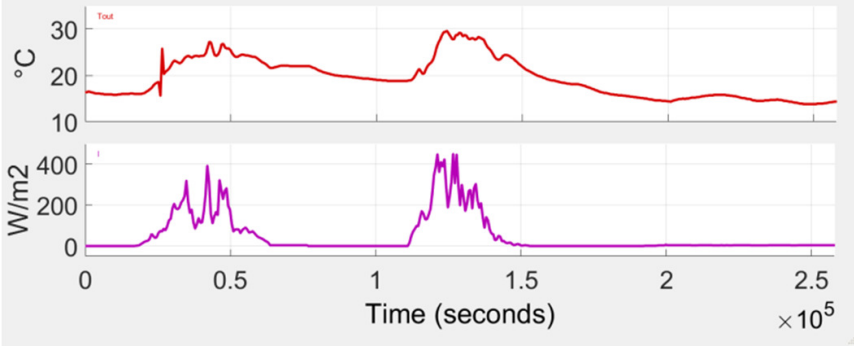

Fig. 11. (a) External temperature profile, (b) solar radiation profile for 1-3 May, 2016.

External Temperature and Solar Radiation Profile for 4 - 6 May, 2016

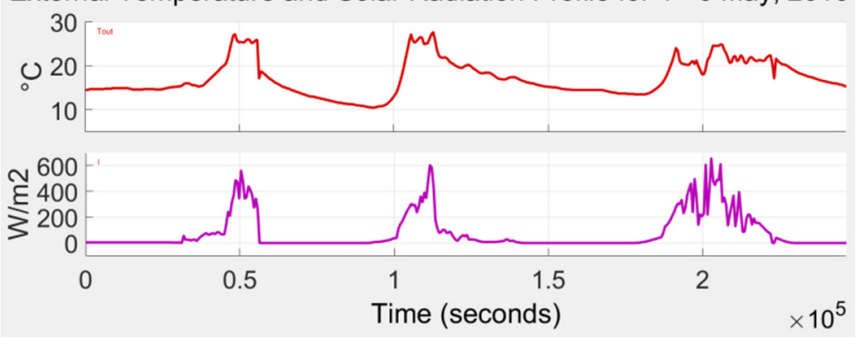

Fig. 12. (a) External temperature profile, (b) solar radiation profile for 4-6 May, 2016.

Figures 10-12 show the hourly variation of solar radiation in the greenhouse and the temperature profile of the different greenhouse components. The greenhouse inside temperature varied from 19 to $25^{\circ} \mathrm{C}$, while the outdoor temperature fluctuated between 6.8 and $32.2^{\circ} \mathrm{C}$. Solar radiation contributed significantly to greenhouse indoor temperature fluctuations, whereas the average indoor daytime temperature was $22^{\circ} \mathrm{C}$. The nighttime greenhouse temperature was mostly stable because an electric heater was turned on for heating purposes. Indoor temperature, wall temperature, and soil temperature during daytime mostly followed a similar trend of solar radiation in the greenhouse because the electric heater was turned off during daytime. Sometimes, mostly at noon, the internal temperature fluctuated, which could be caused by the operation of the natural ventilation system in the greenhouse.

\section{CONCLUSION}

In this paper, a simplified dynamic model of an agricultural greenhouse was developed in Simulink environment in order to predict the dynamic pattern of its internal temperature. The analysis results showed that the internal temperature varies with season (summer, winter, spring or autumn), the external climate parameters (solar radiation, photosynthetically active radiation, wind speed, outside temperature, outside humidity), the location of the greenhouse, the structure of the greenhouse, the number of covers (double or simple) and the cover type. Therefore, the simulation of the internal temperature can be used in making decisions about the location, structure, number of covers, and type of cover materials needed for the construction of a particular greenhouse.

This study developed a steady state thermal model using Matlab/Simulink for the simulation of the heating requirements of the Chinese greenhouse. The model was developed by considering most of the heat sources and sinks in greenhouses including evapotranspiration, the heating contribution of environmental control systems including supplemental lighting, the $\mathrm{CO}_{2}$ generator, and the air-circulation system, which were mostly not considered in previous studies [17, 19]. On this study, it was discovered that the Chinese solar greenhouse has been proved as an energy-efficient horticultural facility for crop production. So, its use could be an alternative option in order to reduce the heating cost of greenhouse production. A simulation model of the internal temperature in a Chinese greenhouse is essential for feasibility studies regarding cold regions. The innovative concept of this study is the introduction of the Simulink block diagram in the modeling of the internal temperature by varying some external factors such as solar radiation and external temperature. The robustness of the Simulink model allows the use of different solvers such as ode4 (Runge-kutta), the step size and the simulation time can also be varied, thereby improving computations. In comparison with previous studies such as [20], only Matlab/Simulink was used to model the internal temperature using the respective equations. The results show the necessity of considering other parameters in the design of greenhouses, especially when the intensity of solar radiation is minimal. Then an alternate source of energy such as geothermal energy will be needed.

\section{REFERENCES}

[1] R. A. Aldrich and J. W. Bartok, Greenhouse Engineering (NRAES 33). Ithaca, N.Y: Northeast Regional Agricultural Engineering Service (NRAES), 1994.

[2] H. A. Ahemd, A. A. Al-Faraj, and A. M. Abdel-Ghany, "Shading greenhouses to improve the microclimate, energy and water saving in hot regions: A review," Scientia Horticulturae, vol. 201, pp. 36-45, Mar. 2016, doi: 10.1016/j.scienta.2016.01.030.

[3] B. Alain, "Greenhouse microclimate and its management in mild winter climates," presented at the International Symposium on Protected Cultivation of Ornamentals in Mild Winter Climates, doi: 10.17660/ ActaHortic.1989.246.1. 
[4] A. Baille, "Trends in greenhouse technology for improved climate control in mild winter climates," Acta Horticulturae, no. 559, pp. 161168, Oct. 2001, doi: 10.17660/ActaHortic.2001.559.23.

[5] V. Castro, S. A. Isard, and M. E. Irwin, "The microclimate of maize and bean crops in tropical America: a comparison between monocultures and polycultures planted at high and low density," Agricultural and Forest Meteorology, vol. 57, no. 1, pp. 49-67, Dec. 1991, doi: 10.1016/01681923(91)90078-5.

[6] O. Körner, J. M. Aaslyng, and N. Holst, "Microclimate Prediction for Dynamic Greenhouse Climate Control," HortScience, vol. 42, no. 2, pp. 272-279, Apr. 2007, doi: 10.21273/HORTSCI.42.2.272.

[7] M. Jomaa, M. Abbes, F. Tadeo, and A. Mami, "Greenhouse Modeling, Validation and Climate Control based on Fuzzy Logic," Engineering, Technology \& Applied Science Research, vol. 9, no. 4, pp. 4405-4410, Aug. 2019.

[8] M. Elashmawy, A. A. A. A. Al-Rashed, L. Kolsi, I. Badawy, N. B. Ali, and S. S. Ali, "Heat Transfer and Fluid Flow in Naturally Ventilated Greenhouses," Engineering, Technology \& Applied Science Research, vol. 7, no. 4, pp. 1850-1854, Aug. 2017.

[9] O. Jolliet and B. J. Bailey, "The effect of climate on tomato transpiration in greenhouses: measurements and models comparison," Agricultural and Forest Meteorology, vol. 58, no. 1, pp. 43-62, Mar. 1992, doi: 10.1016/0168-1923(92)90110-P.

[10] K. A. Joudi and A. A. Farhan, "A dynamic model and an experimental study for the internal air and soil temperatures in an innovative greenhouse," Energy Conversion and Management, vol. 91, pp. 76-82, Feb. 2015, doi: 10.1016/j.enconman.2014.11.052.

[11] O. Jolliet, L. Danloy, J.-B. Gay, G. L. Munday, and A. Reist, "HORTICERN: an improved static model for predicting the energy consumption of a greenhouse," Agricultural and Forest Meteorology, vol. 55, no. 3, pp. 265-294, Jun. 1991, doi: 10.1016/0168-1923 (91)90066-Y.

[12] A. M. Abdel-Ghany and T. Kozai, "Dynamic modeling of the environment in a naturally ventilated, fog-cooled greenhouse," Renewable Energy, vol. 31, no. 10, pp. 1521-1539, Aug. 2006, doi: 10 1016/j.renene.2005.07.013.

[13] M. Azaza, K. Echaieb, A. Mami, and A. Iqbal, "Optimized microclimate controller of a greenhouse powered by photovoltaic generator," in 2014 5th International Renewable Energy Congress (IREC), Mar. 2014, pp. 1-5, doi: 10.1109/IREC.2014.6826937.

[14] Q. Li, D. Zhang, J. Ji, Z. Sun, and Y. Wang, "Modeling of Natural Ventilation Using a Hierarchical Fuzzy Control System for a New Energy-Saving Solar Greenhouse," Applied Engineering in Agriculture, vol. 34, no. 6, pp. 953-962, 2018, doi: 10.13031/aea.12757.

[15] G. Jian-kun, W. Shun-sheng, W. Feng, Y. Hong-guang, and H. Jing, "Modelling Greenhouse Thermal Environment in North China Based on Simulink," Nature Environment and Pollution Technology, vol. 15, no. 1, pp. 217-220, 2016.

[16] M. S. Ahamed, H. Guo, and K. K. Tanino, "Modeling of Heating Requirement in Chinese Solar Greenhouse," presented at the 2016 ASABE Annual International Meeting, Orlando, FL, 2016, doi: 10. 13031/aim.20162455669.

[17] L. Chen, B. Zhang, F. Yao, and L. Cui, "Modeling and simulation of a solar greenhouse with natural ventilation based on error optimization using fuzzy controller," in 2016 35th Chinese Control Conference (CCC), Jul. 2016, pp. 2097-2102, doi: 10.1109/ChiCC.2016.7553676.

[18] J. C. Bakker, G. P. A. Bot, H. Challa, and N. J. van de Braak, Greenhouse climate control: an integrated approach. Netherlands: Wageningen Academic Publishers, 1995.

[19] M. A. Lamrani, T. Boulard, J. C. Roy, and A. Jaffrin, "SE-Structures and Environment: AirFlows and Temperature Patterns induced in a Confined Greenhouse," Journal of Agricultural Engineering Research, vol. 78, no. 1, pp. 75-88, Jan. 2001, doi: 10.1006/jaer.2000.0568.

[20] M. S. Ahamed, H. Guo, and K. Tanino, "Development of a thermal model for simulation of supplemental heating requirements in Chinesestyle solar greenhouses," Computers and Electronics in Agriculture, vol. 150, pp. 235-244, Jul. 2018, doi: 10.1016/j.compag.2018.04.025. 